\title{
THE EFFECTS OF EARLY TOURNIQUET RELEASE DURING TOTAL KNEE ARTHROPLASTY
}

\author{
A PROSPECTIVE RANDOMISED DOUBLE-BLIND STUDY \\ J. BARWELL, G. ANDERSON, A. HASSAN, I. RAWLINGS \\ From Derriford and Mount Gould Hospitals, Plymouth, England
}

We studied the effects of the timing of tourniquet release in 88 patients randomly allocated for release after wound closure and bandaging (group A), or before the quadriceps layer had been closed allowing control of bleeding before suture (group B). The groups were similar in mean age, weight, gender, preoperative knee score, radiographic grading, and prosthesis implanted.

Patients in group B had less postoperative pain, achieved earlier straight-leg raising, and had fewer wound complications. Five patients in group A had to return to theatre, three for manipulation under anaesthesia, one for secondary closure of wound dehiscence, and one for drainage of a haematoma. The last patient later developed a deep infection, which was treated by a two-stage revision. There were no significant differences between the two groups in operating time, or the decrease in haemoglobin concentration at 48 hours postoperatively.

Some of the adverse effects of the use of a tourniquet for knee surgery can be significantly reduced by early tourniquet release, with haemostasis before the quadriceps mechanism and the wound are closed.

J Bone Joint Surg [Br] 1997;79-B:265-8.

Received 20 August 1996; Accepted after revision 1 October 1996

J. Barwell, FRCS, Senior House Officer

G. Anderson, FRCS Orth, FRCS, Consultant Orthopaedic Surgeon

A. Hassan, DrCh Orth, Staff Grade Surgeon

I. Rawlings, FRCS, Consultant Orthopaedic Surgeon

Department of Orthopaedics, Derriford Hospital, Derriford Road, Plymouth PL6 8DH, UK.

Correspondence should be sent to Mr N. J. Barwell at Loe Vean, Feock, Cornwall TR3 6SH, UK.

C1997 British Editorial Society of Bone and Joint Surgery 0301-620X/97/27191\$2.00
The use of a tourniquet may cause muscle and nerve damage. ${ }^{1-3}$ Some recent studies have shown advantages in surgery of the limbs without the use of a tourniquet, ${ }^{4,5}$ but it seems likely, for both practical and traditional reasons, that its general use will continue.

Salam and Eyres ${ }^{5}$ reviewed 80 patients with a total knee arthroplasty who were randomly selected to have the operation under a tourniquet which was released after wound closure and compression bandaging, or without its use. Patients operated on without a tourniquet had no increase in overall blood loss, suffered less postoperative pain, achieved earlier straight-leg raising and flexion, and also had fewer wound and thrombotic complications. They could find no clear explanation for the better results in the nontourniquet group.

Reactive hyperaemia after tourniquet release is reported to cause a $10 \%$ increase in limb size. ${ }^{6}$ If this occurs after wound closure and compression bandaging, bleeding will compound the problem, increasing tissue pressures until tamponade occurs. We investigated whether the advantages reported for tourniquet-free knee surgery could be obtained by releasing the tourniquet and achieving haemostasis before the quadriceps mechanism and skin were closed. This timing was investigated by Burkart et $\mathrm{al}^{7}{ }^{7}$ who randomised 100 consecutive TKAs for tourniquet release with haemostasis before closure and application of compression bandage; or release after this. They found no difference in overall measured blood loss during operation and in the postoperative drainage, but they did not assess the complications or early function after operation.

We combined the protocol of Burkart et al with the outcome measures of Salam and Eyres with the aim of clarifying the reasons for the reduced postoperative complication rate and improved early functional recovery when the tourniquet was not used.

\section{PATIENTS AND METHODS}

We performed TKAs on 88 patients. We excluded those who were diabetic or who had previous open knee surgery. After insertion of the prosthesis the patients were random- 
Table I. Classification of the radiographic features of arthritis of the knee (Holden et al ${ }^{10}$ )

\begin{tabular}{ll}
\hline Grade \\
\hline I $\quad \begin{array}{l}\text { Slight narrowing of joint space, minimal osteophyte formation } \\
\text { and slight sclerosis }\end{array}$ \\
II $\quad \begin{array}{l}\text { Moderate narrowing of joint space, moderate formation of spurs, } \\
\text { moderate sclerosis }\end{array}$ \\
III $\quad \begin{array}{l}\text { Bone-on-bone changes with sclerosis but no severe bone loss } \\
\text { IV } \quad \text { Severe sclerosis, loss of bone stock, obliterated joint space }\end{array}$ \\
\hline
\end{tabular}

Table II. The clinical features of the two groups

\begin{tabular}{|c|c|c|}
\hline & $\begin{array}{l}\text { Group A } \\
(n=44)\end{array}$ & $\begin{array}{l}\text { Group B } \\
(n=44)\end{array}$ \\
\hline Mean age in years (range) & $71(55$ to 87$)$ & $69(48$ to 72$)$ \\
\hline Male:female & $15: 29$ & $12: 32$ \\
\hline Mean weight in kg (range) & 75 (37 to 100$)$ & $77(50$ to 115$)$ \\
\hline Mean HSS score (range) & $53(0$ to 91$)$ & $51(8$ to 91$)$ \\
\hline Median radiographic grade (range) & $2(1$ to 4$)$ & $2(1$ to 4$)$ \\
\hline \multicolumn{3}{|l|}{ Diagnosis } \\
\hline Osteoarthritis & 41 & 41 \\
\hline Rheumatoid arthritis & 3 & 3 \\
\hline \multicolumn{3}{|l|}{ Prosthesis } \\
\hline PFC & 21 & 18 \\
\hline AMK & 10 & 12 \\
\hline IBII & 13 & 14 \\
\hline
\end{tabular}

ised by a sealed-envelope system into two groups. In group A the quadriceps mechanism and skin were closed, and bandages were applied before tourniquet release. In group B the tourniquet was released and haemostasis achieved before closure and bandaging. The first author was not involved in the surgery, but with physiotherapists, was responsible for the postoperative assessment of patients. Information regarding group allocation was kept in theatres and was not available to the assessors or patients.

Thirty of the 44 patients in each group had spinal anaesthesia, using $5 \mathrm{ml}$ of $0.5 \%$ bupivacaine and $0.5 \mathrm{mg}$ of diamorphine injected intrathecally after induction of general anaesthesia. The other 14 patients in each group did not have spinal anaesthesia because of the preference of their anaesthetist. Postoperative pain control was by boluses of 7.5 to $10 \mathrm{mg}$ of morphine given intramuscularly following a standard protocol.

Operative technique. Cephradine $1 \mathrm{~g}$ was given intravenously at induction of anaesthesia and two further doses of $500 \mathrm{mg}$ postoperatively. A pneumatic tourniquet was placed around the thigh, and inflated to twice the systolic blood pressure after elevation of the limb for two minutes.

The prostheses used included: Press-Fit Condylar (Johnson and Johnson Medical Ltd, Bracknell, UK); Anatomical Modular Knee (DePuy International Ltd, Leeds, UK); and Insall-Burstein Mark II (Zimmer Ltd, Swindon, UK). These were implanted using a standard technique through a midline incision. Cut bone surfaces were cleaned by pulsed irrigation before the prostheses were fixed with cement. On the completion of this stage the patient was randomised for group but no record was made in the hospital notes.

In both groups, the quadriceps mechanism was closed with absorbable sutures over two suction drains. Clips were used for the skin. A wool and crepe bandage was then applied and retained for 48 hours, when the drains were removed. The total operating time was recorded.

We did not use continuous passive motion during the first ten postoperative days. Anticoagulant therapy (Clexane $20 \mathrm{mg}$ once daily) was started in the evening after surgery and continued until the patient was fully mobile.

Clinical assessment. Before operation, all patients were weighed and graded for knee pain and function using the hospital for Special Surgery (HSS) score; ${ }^{9}$ the radiographs were assessed according to the classification of Holden et $\mathrm{al}^{10}$ (Table I).

Postoperative pain was measured for all patients on the standard analgesia regime by ward nursing staff using a linear analogue scale at four hours after operation, and the total number of morphine injections required in the first 24 hours was also recorded.

The decrease in haemoglobin concentration from before operation to 48 hours after was calculated, as was information regarding requirements for blood transfusion. The time to achieve straight-leg raising with less than $10^{\circ}$ extension lag, and the range of active knee flexion at five days, ten days and six weeks were documented by physiotherapists. The wound was inspected at five and at ten days postoperatively by the first author. Any excessive swelling of the knee was also recorded.

Statistical analysis. Data were analysed using the MannWhitney U test, the chi-squared test, and Student's $t$-test

Table III. Early postoperative progress

\begin{tabular}{lccl}
\hline & Group A & Group B & p value \\
\hline Median pain score at 4 hours (range)* & $4(0$ to 8$)$ & $1(0$ to 7$)$ & 0.001 (Mann-Whitney U) \\
Median analgesic injections in 24 hours (range) & $1(0$ to 4$) \dagger$ & $1(0$ to 4$)$ & \\
Mean time to straight-leg raise (days) (range) & $5(1$ to 18$)$ & 2.8 (1 to 7$)$ & $<0.00001$ (Student's $t$-test) \\
Mean knee flexion (degrees) (range) & & & \\
$\quad$ Day 5 & $55(15$ to 75$)$ & $60(30$ to 90$)$ & NS (Student's $t$-test) \\
$\quad$ Day 10 & $80(20$ to 95$)$ & $80(55$ to 105$)$ & \\
$\quad$ Week 6 & $90(50$ to 120$)$ & $90(70$ to 110$)$ & NS (Student's $t$-test) \\
Mean days in hospital (range) & $16.3(7$ to 37$)$ & $13.8(5$ to 25$)$ & \\
\hline
\end{tabular}

$* \mathrm{n}=30$, see text

$\dagger$ two patients required intravenous opiate infusions 
Table IV. Operative features and complications

\begin{tabular}{|c|c|c|c|}
\hline & $\begin{array}{l}\text { Group A } \\
(n=44)\end{array}$ & $\begin{array}{l}\text { Group B } \\
(n=44)\end{array}$ & p value \\
\hline Mean operating time (range) & $1 \mathrm{hr} 27$ (47 $\min$ to $2 \mathrm{hr} 09)$ & $1 \mathrm{hr} 31(57 \mathrm{~min}$ to $2 \mathrm{hr} 20)$ & NS (Student's $t$-test) \\
\hline \multicolumn{4}{|c|}{ Median decrease in haemoglobin conc $(\mathrm{g} / \mathrm{dl})$ by $48 \mathrm{hrs}$} \\
\hline Transfused perioperatively (n; range) & $1.3(18 ;-0.8$ to 3.4$)$ & $0.9(22 ;-2.2$ to 3.9$)$ & NS (Mann-Whitney U) \\
\hline Not transfused perioperatively (n; range) & $2.9(26 ; 0.2$ to 6.9$)$ & $3.3(22 ; 0.5$ to 5.0$)$ & NS (Mann-Whitney U) \\
\hline Minor wound complication* & 13 & 6 & 0.04 (chi-squared test) \\
\hline Significant wound complication $\dagger$ & 2 & 0 & NS (chi-squared test) \\
\hline Significant leg swelling $\ddagger$ & 9 & 2 & 0.02 (chi-squared test) \\
\hline Need for manipulation under anaesthetic & 3 & 0 & NS (chi-squared test) \\
\hline Need for revision arthroplasty & 1 & 0 & NS (chi-squared test) \\
\hline
\end{tabular}

* ooze, erythema, cellulitis

$\dagger$ required return to theatre, see text

$\neq$ see text

(Tables II, III and IV). P values less than 0.05 were considered to be significant.

\section{RESULTS}

The groups were similar in respect of age, weight, gender, HSS score, radiographic grade, diagnosis, and ratio of prosthesis employed (Table II). The operating time was similar for both groups.

The pain scores for patients in group B were significantly lower than those of group A (median scores 1 and 4 respectively; $\mathrm{p}<0.001)$. There was no significant difference in the number of injections required in the two groups but two patients in group A required more than the intramuscular opiate in the standard protocol and were given continuous intravenous opiate infusions to control their pain.

Patients in group B were able to perform straight-leg raising significantly earlier than those in group A (mean 2.8 days and 5 days, respectively; $\mathrm{p}<0.00001)$. At five days, the mean range of flexion in patients in group B was $60^{\circ}$ as against $55^{\circ}$ for group $\mathrm{A}$, but this difference was not statistically significant. At ten days and at six weeks the mean ranges of flexion were similar in the two groups.

At 48 hours, the decrease in haemoglobin concentration was similar in both groups, whether or not they had received perioperative blood transfusions. The patients in group A had a mean postoperative stay of 16.3 days as compared with a mean of 13.8 days for group B; this difference was not statistically significant (Table III).

Complications. In group A, 13 patients suffered minor wound complications such as continued oozing after ten days, erythema, cellulitis, or minor dehiscence, as opposed to six in group B $(\mathrm{p}=0.04)$. Nine patients in group A had excessive swelling compared with two in group B $(\mathrm{p}=0.02)$.

No patient in group B had to return to theatre. In group A, three patients required manipulation under anaesthesia for delay in achieving active knee flexion, and one needed secondary suture under anaesthesia for a major wound dehiscence. One other patient in group A required drainage of a haematoma under anaesthesia; this patient later devel- oped a deep infection which was treated by a two-stage revision (Table IV).

\section{DISCUSSION}

We found a reduction in complication rate in our early release group, which was similar to that reported by Salam and Eyres ${ }^{5}$ using no tourniquet. Our results showing reduction in postoperative pain and earlier straight-leg raising after early tourniquet release and control of bleeding also seemed to mirror their findings for tourniquet-free surgery. It is difficult for physiotherapists to mobilise patients safely before they have achieved straight-leg raising, and this therefore was an advantage over the late release group. We did not find a significant improvement, however, in early range of movement.

Two previous studies have shown that release of the tourniquet does not affect overall blood loss during total knee arthroplasty. ${ }^{7,11}$ We did not formally assess this aspect, but the similar decrease in haemoglobin concentration in both groups tends to support this view. ${ }^{11}$

Our study has extended the findings of Salam and Eyres. ${ }^{5}$ A reduction of the tissue tension after operation is achieved by releasing the tourniquet and achieving haemostasis before closure, but reactive hyperaemia and continued bleeding until tamponade will have occurred in the patients in both our groups and in Salam and Eyres' groups. The removal of one of the causes for excessive increase in tension has been shown to achieve some of the benefits of tourniquet-free surgery without losing its benefits during the implantation of the prosthesis.

Anaesthetists prefer to be able to estimate the total blood loss before the patient leaves theatre, and a further advantage of early tourniquet release is that most of the loss occurs before wound closure, while the patient is still under the direct control of the anaesthetist, and not at a later stage during recovery.

The authors wish to thank the operating surgeons, anaesthetists, physiotherapists, ward and theatre staff, and their secretarial support for their contributions to this work.

No benefits in any form have been received or will be received from a commercial party related directly or indirectly to the subject of this article. 


\section{REFERENCES}

1. Dobner J, Nitz A. Postmenisectomy tourniquet palsy and functional sequelae. Am J Sports Med 1982;10:211-4.

2. Sapega AA, Heppenstall RB, Chance B, Park YS, Sokolow D. Optimizing tourniquet application and release times in extremity surgery: a biochemical and ultrastructual study. J Bone Joint Surg [Am] 1985;67-A:303-14.

3. Saunders KC, Louis D, Weingarden SI, Waylonis GW. Effect of tourniquet time on postoperative quadriceps function. Clin Orthop 1979;143:194-9.

4. Salam AA, Eyres KS, Cleary J, El-Sayed HH. The use of a tourniquet when plating tibial fractures. J Bone Joint Surg [Br] 1991; 73-B:86-7.

5. Salam AA, Eyres KS. Effects of tourniquet during total knee arthroplasty. J Bone Joint Surg [Br] 1995;77-B:250-3.
6. Silver R, de la Garza J, Rang M, Koreska J. Limb swelling after release of a tourniquet. Clin Orthop 1986;206:86-9.

7. Burkart BC, Bourne RB, Rorabeck CH, Kirk PG, Nott L. The efficacy of tourniquet release in blood conservation after total knee arthroplasty. Clin Orthop 1994;299:147-52.

8. Klenerman L, Hulands GH. Tourniquet pressures for the lower limb. J Bone Joint Surg [Br] 1979;61-B:124.

9. Insall JN, Dorr LD, Scott WN. Rationale or the Knee Society Clinical Rating System. Clin Orthop 1990;272:13-4.

10. Holden DL, James SL, Arson RL, Slocum DB. Proximal tibial osteotomy in patients who are fifty years old or less: a long term follow-up study. J Bone Joint Surg [Am] 1988;70-A:977-82.

11. Lotke PA, Faralli VJ, Orenstein EM, Ecker ML. Blood loss after total knee replacement. J Bone Joint Surg [Am] 1991;73-A:1037-40. 